\title{
Polysaccharide from wheat bran induces cytokine expression via the toll-like receptor 4-mediated p38 MAPK signaling pathway and prevents cyclophosphamide-induced immunosuppression in mice
}

\author{
Ting Shen ${ }^{\mathrm{a} *}$, Gongcheng Wang ${ }^{\mathrm{b*}}$, Long You ${ }^{\mathrm{a}}$, Liang Zhang ${ }^{\mathrm{a}}$, Haiwei Renc, Weicheng $\mathrm{Hu}^{\mathrm{a}}$, Qian Qiang ${ }^{\mathrm{a}}$, \\ Xinfeng Wang ${ }^{\mathrm{a}}$, Lilian $\mathrm{Ji}^{\mathrm{a}}$, Zhengzhong $\mathrm{Gu}^{\mathrm{a}, \mathrm{d}}$ and Xiangxiang Zhao ${ }^{\mathrm{a}}$
}

\begin{abstract}
ajiangsu Collaborative Innovation Center of Regional Modern Agriculture \& Environmental protection/Jiangsu Key Laboratory for EcoAgricultural Biotechnology around Hongze Lake, Huaiyin Normal University, Huaian, PR China; 'bepartment of Urology, Huai'an First People's Hospital, Nanjing Medical University, Huaian, PR China; 'School of Life Science and Engineering, Lanzhou University of Technology, Lanzhou, PR China; dHuaiyin Institute of Agricultural Science of Xuhuai Region, Huaian, PR China
\end{abstract}

\begin{abstract}
Wheat bran-derived polysaccharides have attracted particular attention due to their immunomodulatory effects. However, the molecular mechanisms underlying their functions are poorly understood. The current study was designed to examine the effect of wheat bran polysaccharide (WBP) on RAW 264.7 cells and the underlying signaling pathways, which have not been explored. In addition, we also investigated the immuno-enhancement effects of WBP on cyclophosphamide (CTX)-induced immunosuppression in mice. WBP significantly increased the concentrations of intracellular nitric oxide (NO) and cytokines such as prostaglandin $E_{2}\left(\mathrm{PGE}_{2}\right)$ and tumor necrosis factor-a (TNF-a) in RAW 264.7 cells. The result of RT-PCR analysis indicated that WBP also enhanced inducible nitric oxide synthase (iNOS), cyclooxygenase-2 (COX-2), and TNF-a expression. Further analyses demonstrated that WBP rapidly activated phosphorylated p38 mitogenactivated protein kinase (MAPK) and the transcriptional activities of activator protein-1 (AP-1) and nuclear factor (NF)-KB via toll-like receptor 4 (TLR4). Furthermore, in vivo experiments revealed that WBP increased the spleen and thymus indices significantly, and markedly promoted the production of the serum cytokines IL- 2 and IFN- $\gamma$ in CTX-induced immunosuppressed mice. Taken together, these results suggest that WBP can improve immunity by enhancing immune function, and could be explored as a potential immunomodulatory agent in functional food.
\end{abstract}

ARTICLE HISTORY

Received 3 March 2017

Accepted 15 June 2017

\section{KEYWORDS}

Wheat bran polysaccharide; immunomodulatory activity; RAW 264.7 macrophages; toll-like receptor 4

\section{Introduction}

Immunostimulation, regarded as one of the body's important defenses, plays a significant role in the host defense mechanism against the invasion of pathogens and antigens. [1] Macrophages derived from blood monocytes can initiate an innate immune response by recognizing infectious agents, and thereby inhibit the growth of a wide variety of tumor cells and invasion of microorganisms.[2,3]

Polysaccharides, as a primary class of biomacromolecules, are composed of monosaccharides and are distributed widely among animals, plants, algae, and fungi.[4] In recent years, numerous polysaccharides isolated from natural resources have been demonstrated to possess a broad spectrum of therapeutic properties such as antioxidant, anti-cancer, and immune-modulating activities, and have been used widely in the food and pharmaceutical industries.[5-7] Several plant polysaccharides have been regarded as important immunostimulant candidates due to their ability to enhance the activation of macrophages with no significant side effects and low toxicity.[8] When activated, macrophages can kill pathogens directly by phagocytosis and indirectly through secreting inflammatory mediators such as nitric oxide (NO), prostaglandin $\mathrm{E}_{2}$ $\left(\mathrm{PGE}_{2}\right)$, tumor necrosis factor- $\alpha$ (TNF- $\alpha$ ), interleukin- $1 \beta$ (IL-1 $\beta$ ), and IL-6. $[9,10]$ Polysaccharide-mediated immune cell stimulation can occur via binding to pattern recognition receptors (PRRs) on the surface of macrophages such as toll-like receptors (TLRs), Dectin-1, and complement receptor type 3 (CR3), and trigger a series of signal transduction pathways including phosphoinositide-3-kinase (PI3K)/Akt, mitogen-activated protein kinases (MAPKs), as well as transcription factors such as nuclear factor (NF)$\kappa \mathrm{B}$ and activator protein (AP)-1.[11,12]

Wheat bran, the outer layer of the wheat kernel, is produced worldwide as a major by-product of the wheat milling industry; it accounts for about $14-19 \%$ of the grain 
weight.[13] Previous research has confirmed that wheat bran contains the bulk of high-value components, such as non-starch polysaccharides, fatty acids, tocopherols, and phenolic compounds.[14] However, only a small portion of wheat bran is currently utilized, mostly as low-value livestock feed. In recent years, wheat bran polysaccharides have drawn attention for their demonstrated health benefits derived from antioxidant, immunostimulatory, anticomplementary, and antitumor activities.[15-17] Despite previous studies that focused on immunoregulatory activities of wheat bran polysaccharide (WBP) in in vivo models, the underlying mechanisms of these pharmacological actions have been barely explored at the cellular and molecular levels. The aim of the current study was to evaluate the immunostimulatory effect of WBP by employing in vitro and in vivo experiments, and to investigate the underlying molecular mechanism.

\section{Materials and methods}

\section{Material and chemicals}

Fresh wheat bran was provided by Huaiyin Institute of Agricultural Science of Xuhuai Region (Jiangsu, China) from a local wheat cultivar Huaimai 33. A voucher specimen (WBH-160,608) was deposited in Jiangsu Collaborative Innovation Center of Regional Modern Agriculture \& Environmental Protection, Huaiyin Normal University, China. 1-(4,5Dimethylthiazol-2-yl)-3,5-diphenylformazan (MTT), lipopolysaccharide (LPS), dimethyl sulfoxide (DMSO), sulfanilamide, naphthylethylenediamine dihydrochloride, and monosaccharide standards were purchased from Sigma-Aldrich (St Louis, MO, USA). Cyclophosphamide (CTX) was purchased from Jiangsu Hengrui Medicine Co. (Jiangsu, China). Bovine serum albumin (BSA) was acquired from Bioworld (Dublin, OH, USA). The Roswell Park Memorial Institute (RPMI) medium, phosphate-buffered saline (PBS, $\mathrm{pH}$ 7.4), and penicillinstreptomycin solution were from Gibco BRL (Life Technologies, Shanghai, China). Fetal bovine serum (FBS) was obtained from HyClone (Thermo Fisher Scientific, Logan, UT, USA). All the primary antibodies were obtained from Cell Signaling Technology (Beverly, MA, USA). The secondary antibody was purchased from Abcam (Cambridge, MA, USA). Enhanced chemiluminescence (ECL) detection reagent and bicinchoninic acid (BCA) protein assay kit were from CoWin Biosciences (Beijing, China). Enzyme-linked immunosorbent assay (ELISA) kits for $\mathrm{PGE}_{2}$ and TNF- $\alpha$ were from R\&D Systems
(Minneapolis, MN, USA). Polyvinylidene fluoride (PVDF) membrane was obtained from BioRad (Hercules, CA, USA). All other chemicals and solvents were analytical reagent grade.

\section{Extraction of crude polysaccharide}

The wheat bran powder $(1.0 \mathrm{~kg})$ was refluxed with petroleum ether for $24 \mathrm{~h}$ to remove lipids and pigments. Then, the resulting residue was air-dried and extracted with deionized water at $100^{\circ} \mathrm{C}$ for $3 \mathrm{~h}$. After vacuum filtration, the supernatant was concentrated to one-third of its initial volume using a vacuum rotary evaporator (RE-3000;YaRong Biochemistry Instrument Factory, Shanghai, China) at $55^{\circ} \mathrm{C}$. The resulting concentrated liquor was deproteinized three times by an equal volume of Savage solution (chloroform:butyl alcohol in 4:1 ratio), and the deproteinized solution was mixed with a triple volume of absolute ethanol, stirred vigorously and left overnight at $4^{\circ} \mathrm{C}$. The precipitate was collected by centrifugation at $6000 \times \mathrm{g}$ for $10 \mathrm{~min}$ and washed with absolute ethanol. Afterward, the precipitate was redissolved in deionized water and dialyzed in a dialysis bag (cutoff molecular weight: $7000 \mathrm{Da}$ ) and then freeze-dried to afford WBP.

\section{Chemical and monosaccharide composition}

The total sugar content of WBP was estimated by the phenol-sulfuric acid method using glucose as a standard.[18] The total protein content was determined using the BCA protein assay kit and BSA was used as the standard. The uronic acid content was determined by sulfamate/m-hydroxydiphenyl assay using glucuronic acid as a standard, and the sulfate content of the polysaccharide was determined by the $\mathrm{BaCl}_{2}$ gelatin method using $\mathrm{K}_{2} \mathrm{SO}_{4}$ as a standard.[19]

Monosaccharide content of the sample was determined according to the following steps. In brief, $40 \mathrm{mg}$ of WBP was hydrolyzed with $1 \mathrm{ml} 4 \mathrm{M}$ trifluoroacetic acid (TFA) at $100^{\circ} \mathrm{C}$ for $12 \mathrm{~h}$ in a sealed flask. The hydrolysate was evaporated to dryness under a nitrogen blowing instrument. Then, $10 \mathrm{mg}$ of hydroxylamine hydrochloride and $0.5 \mathrm{ml}$ pyridine were added to the sealed flask, incubating in a water bath for $30 \mathrm{~min}$ at $90^{\circ} \mathrm{C}$. After cooling, $0.5 \mathrm{ml}$ of acetic anhydride was added and incubated in a water bath at $90^{\circ} \mathrm{C}$ for $30 \mathrm{~min}$ again. The acetylated derivative was extracted in $1.0 \mathrm{ml}$ chloroform and the acetylated part was analyzed by gas chromatography (GC, Agilent 7890A, Palo Alto, CA, USA) using a DM-5 capillary column (30 $\mathrm{m} \times$ $0.2 \mathrm{~mm}$, film thickness $0.25 \mu \mathrm{m}$ ). 


\section{Fourier-transform infrared (FT-IR) spectroscopy analysis}

The FT-IR spectrum of WBP was recorded on a Nicolet IS50 FT-IR Spectrometer (Thermo Scientific, Waltham, MA, USA) in the wavenumber range of $4000-500 \mathrm{~cm}^{-1}$ with a resolution of $2 \mathrm{~cm}^{-1}$.

\section{Cell line and cell culture}

RAW 264.7 macrophages were obtained from American Type Culture Collection (Manassas, VA, USA). Cells were cultured in RPMI 1640 culture medium supplemented with $10 \%$ heat-inactivated FBS and $1 \%$ antibiotics (100 $\mathrm{U} \mathrm{ml}^{-1}$ penicillin and $100 \mu \mathrm{g} \mathrm{ml}^{-1}$ streptomycin), and maintained at $37^{\circ} \mathrm{C}$ in a humidified atmosphere of $95 \%$ air and $5 \% \mathrm{CO}_{2}$. Confluent cells were passaged by scraping them with a sterile cell scraper.

\section{Cell viability assay}

The effect of WBP on the viability of RAW 264.7 cells was determined colorimetrically using the MTT method. [20] Briefly, $100 \mu \mathrm{l}$ RAW 264.7 cells $\left(1 \times 10^{6}\right.$ cells ml $\left.{ }^{-1}\right)$ were seeded in a 96-well plate. After $24 \mathrm{~h}$ incubation, cells were treated with increasing concentrations of the WBP $\left(0-1000 \mu \mathrm{g} \mathrm{ml}^{-1}\right)$ for $24 \mathrm{~h}$ in a final volume of $200 \mu \mathrm{l}$. Then, the medium was removed carefully and $100 \mu \mathrm{l}$ of MTT (0.5 mg ml$~^{-1}$ in FBS-free medium) was added to each well and incubated for additional $4 \mathrm{~h}$. After incubation, the purple formazan crystals were dissolved in $100 \mu \mathrm{l}$ of MTT stop solution that contains $10 \%$ SDS and $0.01 \mathrm{M}$ hydrochloric acid. The absorption values were measured at $550 \mathrm{~nm}$ on a multifunctional microplate reader (Infinite M200 Pro spectrophotometer, Tecan, Switzerland). The optical density of the formazan formed in vehicle control was taken as $100 \%$ of viability.

\section{Determination of NO, $\mathrm{PGE}_{2}$, and TNF-a production}

RAW 264.7 cells were seeded at the density of $1 \times 10^{5}$ cells/well in 96-well culture plates. After $24 \mathrm{~h}$ incubation, cells were treated with increasing concentrations of the WBP $\left(0-100 \mu \mathrm{g} \mathrm{m}^{-1}\right)$ for $24 \mathrm{~h}$ in a final volume of $200 \mu \mathrm{l}$. The cell treated with LPS was used as the positive control. At the end of incubation, the supernatant was collected and stored at ultra-low temperature freezer. The production of NO, $\mathrm{PGE}_{2}$, and TNF- $\alpha$ was quantified using the Griess reagent and ELISA kits as described previously.[21] Standard curves were used for calculation of cytokine concentration.

\section{RNA extraction and reverse transcription- polymerase chain reaction (RT-PCR)}

A total of $5 \times 10^{6}$ cells were plated per well in $60-\mathrm{mm}$ cell culture plates with $4 \mathrm{ml}$ culture medium for $16 \mathrm{~h}$ and exposed to $100 \mu \mathrm{g} \mathrm{ml}^{-1} \mathrm{WBP}$ for the indicated time points. Total RNA was isolated with TRIzol reagent (Invitrogen, Carlsbad, CA, USA) in accordance with manufacturer's instructions. The quantity and quality of the total RNA were determined by a UV spectrophotometer (Nanodrop 2000c, Thermo Scientific, Wilmington, DE, USA) and denaturing RNA electrophoresis. An amount of $2 \mu \mathrm{g}$ total RNA was converted into cDNA using the Revert Aid First Strand cDNA Synthesis Kit (Fermentas, Waltham, MA, USA). The primer sequences and conditions used in the PCRs are listed in Table 1. Semi-quantitative PCR were performed as reported previously.[22]

\section{Transfection and luciferase reporter assay}

The RAW 264.7 cells $\left(5 \times 10^{5}\right.$ cells/well $)$ were seeded into 24-well plates in complete medium without antibiotics and grew to about $90 \%$ confluence. Cells were transfected with NF- $\kappa \mathrm{B}-\mathrm{Luc}$ or AP-1-luc reporter plasmid by using the lipofectamine 3000 (Invitrogen) according to the manufacturer's instructions. After that, the cells were washed with fresh medium and treated with different concentration of WBP for $1 \mathrm{~h}$. Then, the cells were lysed in $1 \times$ reporter lysis buffer and the luciferase activities were measured using the Promega luciferase assay system (Promega, Madison, CA, USA).

Table 1. Primer sequences and conditions for RT-PCR.

\begin{tabular}{llcc}
\hline Target genes & \multicolumn{1}{c}{ Primer sequence $\left(5^{\prime}-3^{\prime}\right)$} & Annealing $T_{m}\left({ }^{\circ} \mathrm{C}\right)$ & PCR cycles \\
\hline GAPDH & F: CACTCACGGCAAATTCAACGGCA & 60 & 30 \\
R: GACTCCACGACATACTCAGCAC & & 27 \\
F: CCCTCCGAGTTCTGGCAGCAG & $\begin{array}{l}\text { R: GGCTGTCAGAGCCTCGTGGCTTTGG } \\
\text { F: CACTACATCCTGACCCACTT } \\
\text { R: ATGCTCCTGCTTGAGTATGT } \\
\text { FNF-a }\end{array}$ & 50 & 30 \\
& R: GAGCTATGTCTCAGCCTCTTC & 55 & 30 \\
\hline
\end{tabular}




\section{Cell lysis and immunoblotting}

A total of $5 \times 10^{6}$ cells were plated per well in $60-\mathrm{mm}$ cell culture plates with $4 \mathrm{ml}$ culture medium for $16 \mathrm{~h}$ and exposed to $100 \mu \mathrm{g} \mathrm{ml}^{-1} \mathrm{WBP}$ for the indicated time points. The whole cell extract and nuclear protein were prepared using RIPA lysis buffer and nuclear protein isolation kit (CoWin Biosciences) according to the provided protocols and the protein concentrations were calculated using a BCA protein assay kit. Cell extracts were separated by sodium dodecyl sulfate (SDS)-polyacrylamide gel electrophoresis (PAGE) and the resolved proteins were electroblotted onto PVDF membranes with a glycine transfer buffer. Immunoblotting analysis was performed as described previously.[23] Protein bands were then visualized using enhanced chemiluminescence detection reagent using the Tanon-5200 chemiluminescence detection system (TanonScience, Shanghai, China). Densitometric analysis was done using Quantity One software (Bio-Rad, Munich, Germany) and calculated by a ratio to a housekeeping control.

\section{Animals and treatments}

C57BL/6 mice (eight weeks old) weighing 20-22 g were provided by Shanghai Laboratory Animal Center (Shanghai, China) and maintained under controlled environmental conditions $\left(22 \pm 3^{\circ} \mathrm{C}, 50 \% \pm 10 \%\right.$ humidity) on a 12-h light/12-h dark cycle. All animals were allowed free access to standard pellet diet and water throughout the experiment. All experiments were performed in strict accordance with the guidelines of the Committee of Nanjing Medical University. Mice were randomly divided into five groups (Table 2) for various treatments, each containing 10 mice. Control mice were injected with $0.9 \%$ sodium chloride solution. The immunosuppression groups were treated intraperitoneally (i.p.) with cyclophosphamide (CTX) at a dose of $30 \mathrm{mg} \mathrm{kg}^{-1}$ for 1-3 days. The CTX-treated mice were administered intragastrically (i.g.) with saline solution or different dose of WBP daily for 10 days. At $24 \mathrm{~h}$ after the last WBP administration, the eyes of the animals under anesthesia were removed to take blood samples and then the mice were killed by cervical vertebra dislocation. Blood was allowed to clot, and serum was separated by centrifugation at $3000 \mathrm{rpm}$ for $15 \mathrm{~min}$.

Table 2. Group classification of C57BL/6 mice.

\begin{tabular}{ll}
\hline Group & \multicolumn{1}{c}{ Treatment } \\
\hline Normal & Control mice +vehicle treatment \\
CTX & CTX $30 \mathrm{mg} \mathrm{k}^{-1}$ (i.p.) \\
CTX + low dose WBP & CTX $30 \mathrm{mg} \mathrm{kg}^{-1}$ (i.p.) $+50 \mathrm{mg} \mathrm{kg}^{-1}$ WBP (i.g.) \\
CTX + medium dose WBP & CTX $30 \mathrm{mg} \mathrm{kg}^{-1}$ (i.p.) $+100 \mathrm{mg} \mathrm{kg}^{-1}$ WBP (i. \\
& g.) \\
CTX + high dose WBP & CTX $30 \mathrm{mg} \mathrm{kg}^{-1}$ (i.p.) $+200 \mathrm{mg} \mathrm{kg}^{-1}$ WBP (i.g.) \\
\hline
\end{tabular}

The levels of IL- 2 and IFN- $\gamma$ were estimated using standard kits. The spleen and thymus were collected and immediately weighed to calculate the spleen and thymus indices.

\section{Statistical analysis}

All experiments were carried out independently in triplicate and the data are expressed as mean \pm standard deviation (SD). One-way analysis of variance (ANOVA) was used to determine the significant differences between the groups, followed by a Student's $t$-test. Values of $p$ less than 0.05 were considered as significant. All analyses were performed using SPSS 20 (SPSS Inc., Chicago, IL, USA).

\section{Results and discussion}

\section{Physicochemical properties of WBP}

We determined the chemical composition of WBP and the results are listed in Table 3. The yield of polysaccharides from wheat bran was $9.23 \%(\mathrm{w} / \mathrm{w})$ and the sugar content was $39.67 \%(\mathrm{w} / \mathrm{w})$. This yield was lower than that obtained using an alkaline-extraction process (unpublished data). It is well known that protein by amide bond and ferulic acid are bonded with polysaccharide by a covalent ester bond to form the water-insoluble polymer. An alkali solution can break covalent bonding and is conducive to the dissolution of polysaccharides from wheat bran.[23] Before investigating the possible molecular mechanism of the immunostimulatory effect of WBP, we compared the efficiencies of the alkaline-extracted and water-extracted polysaccharide. We found that water-extracted polysaccharide showed higher immunological activities. In the subsequent work, we used the water-extraction process for polysaccharide isolation.

Following Savage agent treatment, the protein content was $4.56 \%$. The presence of protein was consistent with the UV spectrum analysis; there was a weak absorption at $260-280 \mathrm{~nm}$ (data not shown).

Table 3. Composition and physicochemical characteristic of WBP.

\begin{tabular}{|c|c|}
\hline Sample & WBP \\
\hline Yield $(\%)^{\mathrm{a}}$ & $9.32 \pm 1.03$ \\
\hline Carbohydrate $(\%)^{\mathrm{b}}$ & $39.67 \pm 4.58$ \\
\hline Protein $(\%)^{\mathrm{b}}$ & $4.56 \pm 0.75$ \\
\hline Uronic acid $(\%)^{\mathrm{b}}$ & $4.21 \pm 0.36$ \\
\hline Sulfate group content $(\%)^{\mathrm{b}}$ & $3.26 \pm 0.43$ \\
\hline \multicolumn{2}{|l|}{ Monosaccharide mole ratio } \\
\hline $\mathrm{Ara} / \mathrm{Xyl} / \mathrm{Glu}^{\mathrm{c}}$ & $1: 1.07: 0.13$ \\
\hline
\end{tabular}


Similar protein levels were reported by Zhou et al. [24] for alkaline-extracted arabinoxylans from wheat bran $(4.10 \%)$. Proteins can also be extracted during hot-water extraction due to water solubility as well as the carbohydrate-protein linkages.[25] The free protein in WBP was removed using the Savage method. Thus, the detected proteins were considered to be bound to polysaccharides. In addition, we determined the contents of uronic acid and sulfate group content in WBP to be 4.21 and $3.26 \%(\mathrm{w} / \mathrm{w})$, respectively.

We analyzed the monosaccharide components of WBP quantitatively by GC. Compared with standard monosaccharide derivatives, the results indicated that WBP contained mainly arabinose, xylose, and glucose. The molar ratio of the monosaccharides (arabinose: xylose:glucose) was approximately 1:1.07:0.13. Arabinose and xylose were clearly the dominant sugars in the extracted polysaccharide. These results are in agreement with other studies that reported that cell wall polysaccharides in wheat bran are formed mainly by arabinogalactan.[26,27]

The FT-IR spectrum of wheat bran polysaccharide is shown in Figure 1. Characteristic absorption peaks near $3374,2928,1666,1412,1150,1027$, and $849 \mathrm{~cm}^{-1}$ were observed. The broad band at $3374 \mathrm{~cm}^{-1}$ was attributed to the characteristic peak of $\mathrm{O}-\mathrm{H}$ stretching vibrations and the peak at $2928 \mathrm{~cm}^{-1}$ represented $\mathrm{C}-\mathrm{H}$ stretching vibration. These signals corresponded to the typical absorption values of polysaccharides.[28] In addition, the spectrum displayed the signals at $1666 \mathrm{~cm}^{-1}$ and $1412 \mathrm{~cm}^{-1}$, which were due to the asymmetric and symmetric stretching of a deprotonated carboxylic group of uronic acid and protein. The bands at $1150 \mathrm{~cm}^{-1}$ and $1027 \mathrm{~cm}^{-1}$ should be ascribed to the C-O-C stretching vibration.[29]

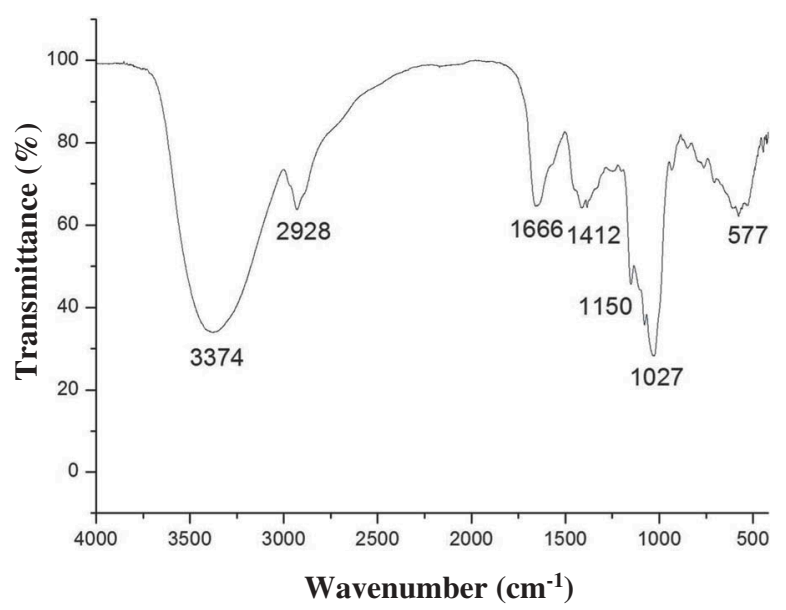

Figure 1. The FT-IR spectrum of WBP isolated from wheat bran.

\section{Effects of WBP on the production of inflammatory mediators}

Prior to evaluating the immunostimulatory activity of WBP, we evaluated the cytotoxic effect with respect to RAW 264.7 cells using the MTT assay for doses ranging from 25 to $1000 \mu \mathrm{g} \mathrm{ml}^{-1}$. The results indicated that all WBP doses tested did not affect cell viability relative to the negative control (Figure 2(a)). The concentrations used in the subsequent studies were based on these results. We evaluated the immunostimulatory activity of WBP by measuring the accumulation of NO in the RAW 264.7 macrophage cell supernatant. RAW 264.7 murine macrophage cells were incubated along with the WBP or LPS ( $1 \mu \mathrm{g} \mathrm{ml}^{-1}$, positive control) for $24 \mathrm{~h}$ and NO concentrations in the culture supernatants were measured using the Griess reagent. As shown in Figure 2(b), a minimal amount of NO $(2.35 \mu \mathrm{M})$ was released when RAW 264.7 cells were exposed to medium alone, whereas incubation of these cells with increasing amounts of WBP $\left(12.5,25,50\right.$, or $\left.100 \mu \mathrm{g} \mathrm{ml}{ }^{-1}\right)$ was associated with a concentration-dependent increase in $\mathrm{NO}$ production (2.58-, 11.07-, 17.08-, and 22.45-fold, respectively), suggesting that WBP significantly induced the production of NO from RAW 264.7 cells in a dose-dependent manner. To examine whether WBP-activated RAW 264.7 cells produced cytokines, the culture supernatants were collected at $24 \mathrm{~h}$, and the amounts and concentrations of TNF- $\alpha$ and PGE in $_{2}$ the supernatant were detected using an ELISA kit. As shown in Figure 2(c) and 2(d), stimulation of RAW 264.7 macrophages with WBP for $24 \mathrm{~h}$ induced higher levels of secreted cytokines relative to the control group. Moreover, polymyxin B (PolyB), an antibiotic recognized for its LPS-neutralizing effect, was used to confirm that the effect of WBP was not due to endotoxin contamination. As shown in Figure 2(b-d), pre-incubation with $\mathrm{PMB}$ did not decrease $\mathrm{NO}, \mathrm{PGE}_{2}$, or TNF- $\alpha$ production by macrophages stimulated with WBP. Additionally, PMB abolished LPS-induced inflammatory cytokines in RAW 264.7 cells. These results demonstrated that the observed immunostimulatory activity of the WBP did not originate from endotoxin contamination. Immunostimulation is regarded as an important strategy for improving the host self-defense mechanism in elderly people, as well as in cancer patients.[30] During activation, macrophages initiate phagocytosis and release proinflammatory cytokines and other substances, a hallmark of pneumococcal pneumonia, which is necessary for killing microorganisms and invading pathogens, and mediate a variety of biological functions as intracellular messenger molecules.[31,32] These results demonstrated that WBP could markedly stimulate macrophage functions. 
a

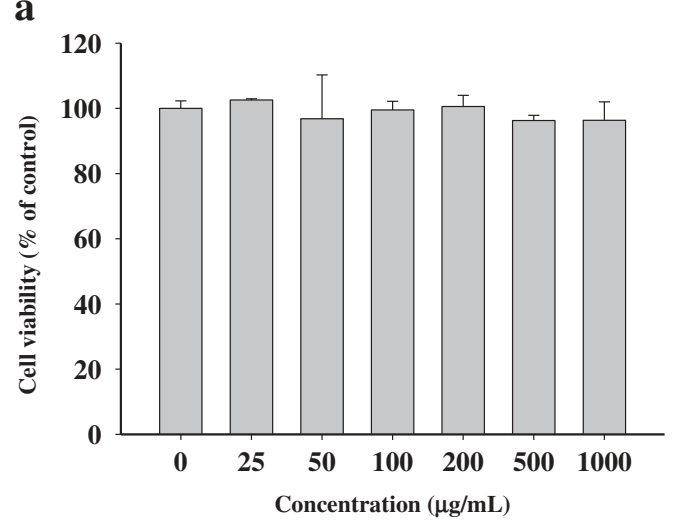

C

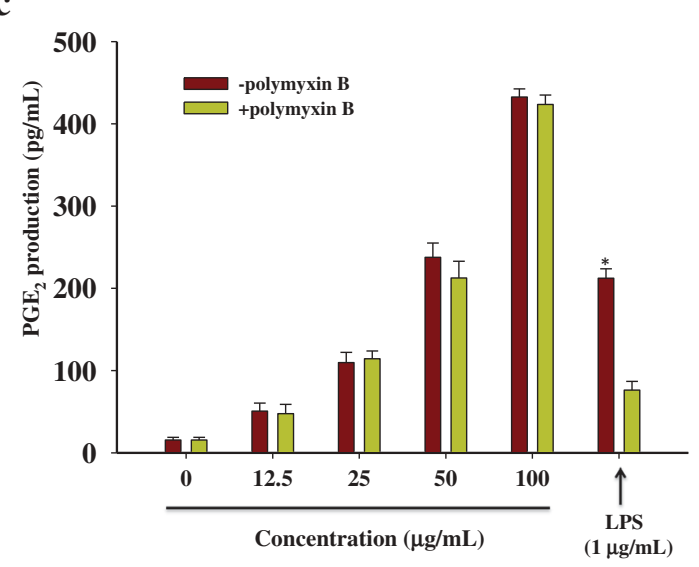

b

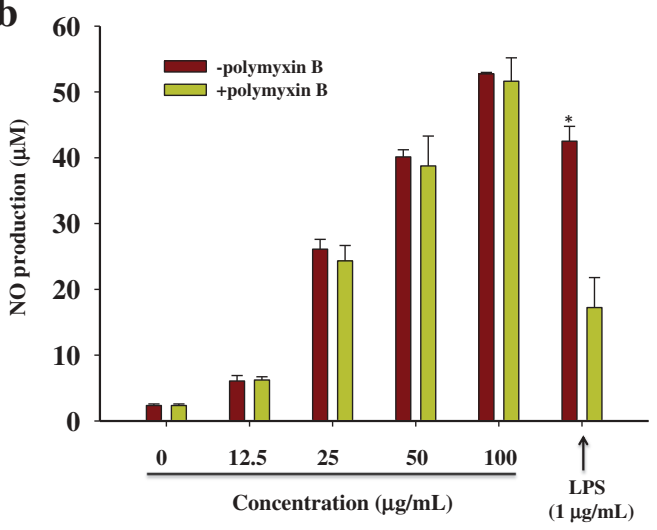

d

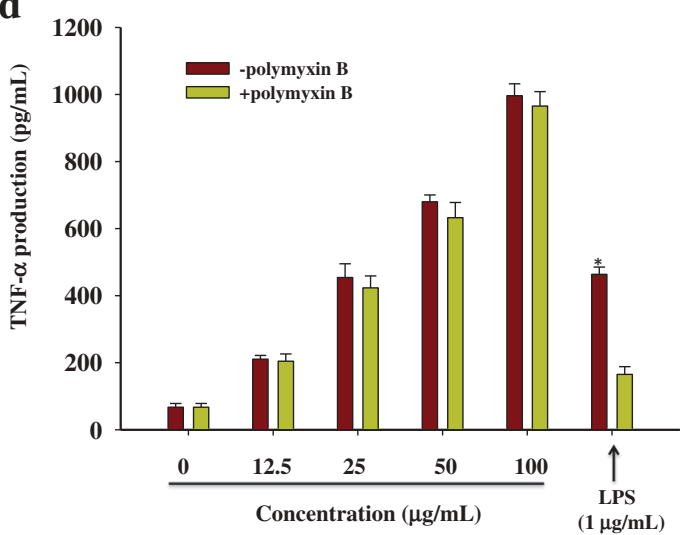

Figure 2. The effects of WBP on cytokines secretion in RAW 264.7 cells. (a) RAW 264.7 cells were treated with WBP at the various concentrations for $24 \mathrm{~h}$ and the cell viability was determined using an MTT assay. (b-d) The RAW 264.7 cells were cultured with $12.5,25,50$ or $100 \mathrm{ug} \mathrm{ml}^{-1}$ of WBP for $24 \mathrm{~h}$. In order to rule out possible endotoxin contamination, WBP or LPS were pretreated with polymyxin $B\left(100 \mu \mathrm{g} \mathrm{ml}^{-1}\right)$ for 30 min before challenging RAW 264.7 cells. The level of NO was detected by Griess reagent; PGE 2 and TNF- $a$ were measured by ELISA kits. Each value is the mean \pm standard deviation $(n=3)$. Any significant differences between polymyxin B-treated and -untreated groups were analyzed using the Student's $t$-test $\left({ }^{*} p<0.05\right)$.

\section{Effects of WBP on the expression of inflammatory genes}

Among three nitric oxide synthase (NOS) isoforms, iNOS is known as the main enzyme responsible for the production of NO in activated macrophages, which is involved in the elimination of aberrant cells and microbial pathogens. [33] Expression of pro-inflammatory cytokines, including COX-2, TNF- $\alpha$, IL- $1 \beta$, and IL-6, is essential for host survival from infection and they are recognized as important host defense molecules that affect tumor cells.[34] To determine whether the increases in $\mathrm{NO}, \mathrm{PGE}_{2}$, and TNFa secretion are attributable to increased expression of iNOS, COX-2, and TNF- $\alpha$, cells were treated with $100 \mu \mathrm{g} \mathrm{ml}^{-1}$ WBP for $10,60,180$, and $360 \mathrm{~min}$ and proinflammatory cytokine mRNA levels were measured by semi-quantitative RT-PCR (Figure 3). iNOS, COX-2, and TNF- $\alpha$ mRNAs were barely detectable in unstimulated RAW cells; however, following WBP stimulation, the mRNA levels for all these inflammatory factors increased significantly. By contrast, the control house-keeping gene was expressed constitutively and was not affected by the treatment with WBP. Published data showed that polysaccharides induced the production of pro-inflammatory factors in RAW 264.7 cells by upregulating their gene expression.[35,36] Thus, these results strongly suggest that the increased production of NO, PGE 2 , and TNF- $\alpha$ in the macrophages occurs through upregulated mRNA expression of NOS, COX-2, and TNF- $\alpha$, which is consistent with the previous findings.[37] WBP treatment at 60 min enhanced TNF- $\alpha$ mRNA expression, while it had less of an effect on iNOS expression. Recent studies have demonstrated that TNF- $\alpha$ is the first compound of the TNF- $\alpha$ and NO series to be secreted by macrophages.[38] Thus, TNF- $\alpha$ is involved in the early phase of the cytokine cascade and induces NO production.

\section{Effect of WBP on TLR4-mediated signaling pathway}

NF- $\kappa \mathrm{B}$ and AP-1 are key transcription factors that facilitate the expression of various genes involved in immune 


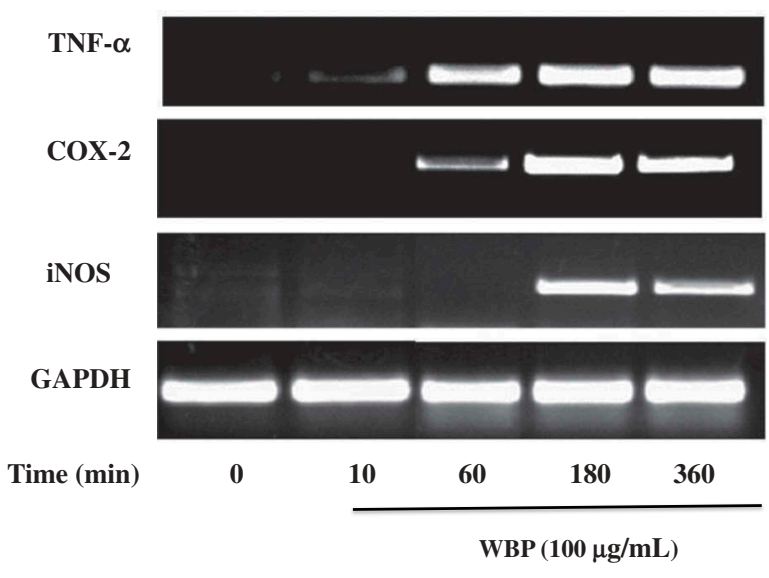

Figure 3. The effect of WBP on the expression of mRNAs of iNOS, COX-2, and TNF- $a$ in RAW 264.7 cells. RAW 264.7 cells $\left(5 \times 10^{6}\right.$ cells $\left.\mathrm{ml}^{-1}\right)$ were incubated with $100 \mu \mathrm{g} \mathrm{ml}^{-1}$ WBP for the indicated periods of time. Total RNA was isolated and the expression of iNOS, COX-2, and TNF- $a$ was determined by semiquantitative PCR as described in the text. A representative gel graph from three independent experiments was shown.

and inflammatory responses including iNOS, TNF- $\alpha$, and IL-6.[39] The promoters of the iNOS and COX-2 genes contain several homologous consensus sequences for the binding of NF- $\mathrm{kB}$ and AP-1.[40] To further investigate the possible involvement of NF- $\mathrm{KB}$ and $\mathrm{AP}-1$ in the induction of pro-inflammatory mediators by WBP, we employed a luciferase (Luc) reporter gene assay using NF$\kappa B$-Luc and AP-1-Luc constructs in RAW 264.7 cells. As shown in Figure 4(a), after stimulation with 0.0, 12.5, 25, 50 , and $100 \mu \mathrm{g} \mathrm{ml}^{-1} \mathrm{WBP}$, the fold-increases in NF- $\mathrm{BB}$ -mediated Luc activity were $1.00 \pm 0.23$ (control group), $5.76 \pm 2.78,11.67 \pm 1.85,14.57 \pm 3.21$, and $20.65 \pm 5.98$, respectively. Moreover, the fold-increases in AP-1mediated Luc activity in cells treated with $0.0,12.5,25$, 50 , and $100 \mu \mathrm{g} \mathrm{ml}^{-1} \mathrm{WBP}$ were $1.00 \pm 0.15$ (control), $2.35 \pm 1.89,6.89 \pm 2.34,10.75 \pm 1.24$, and $15.23 \pm 4.39$, respectively (Figure 4(b)). Furthermore, immunoblot analysis with specific antibodies of cells stimulated with $100 \mu \mathrm{g} \mathrm{ml}^{-1}$ WBP for various incubation times revealed the expression levels of nuclear p65, a key NF- $\mathrm{kB}$ subunit, and c-Jun and c-fos. As shown in Figure 4(c), the levels of the AP-1 subunits were most increased after treatment with WBP for $5 \mathrm{~min}$, after which decreased was observed. Moreover, the level of p65 reached a maximum in $5 \mathrm{~min}$. These results suggest that the translocation of NF- $\kappa B$ and AP-1 from the cytosol to the nucleus is involved in macrophage stimulation by WBP.

MAPKs belong to a family of serine/threonine-specific protein kinases that are involved in the ERK, JNK, and

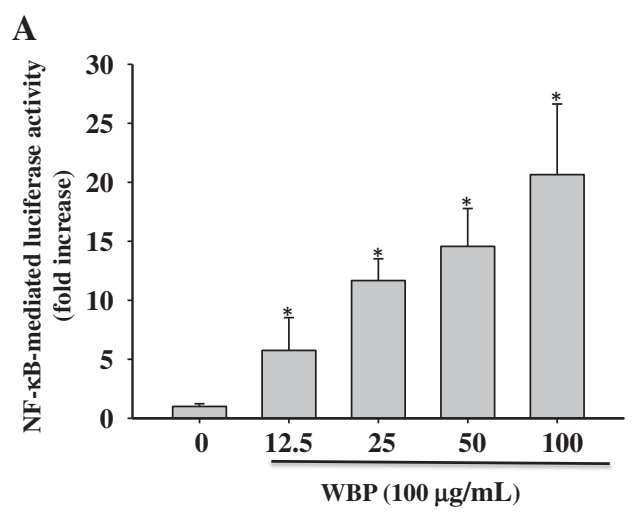

B

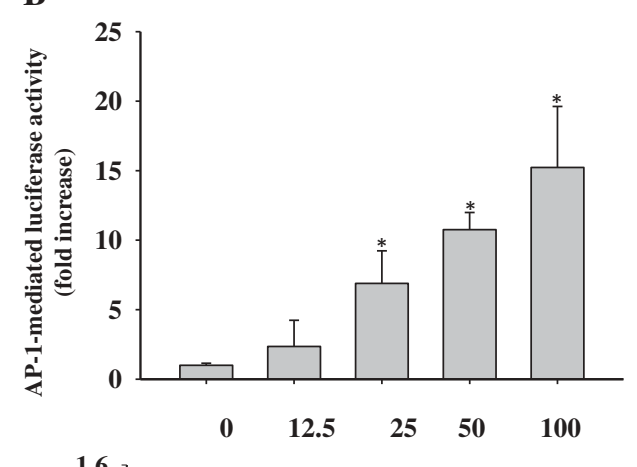

C

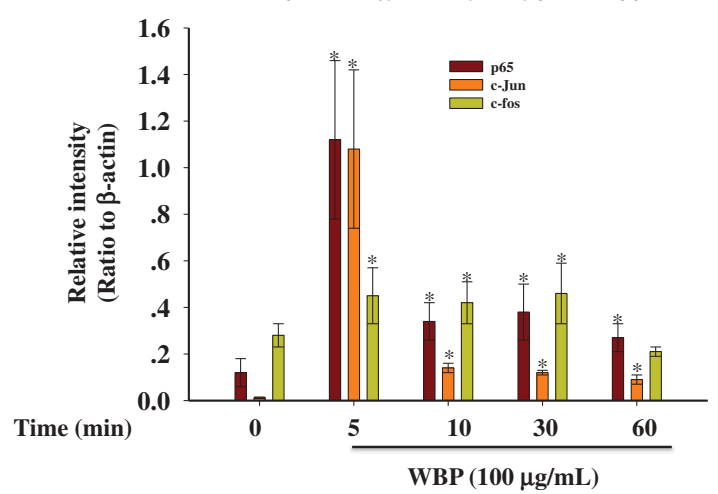

Figure 4. Effect of WBP on the nuclear translocation of NF-KB and AP-1. RAW 264.7 cells were transiently co-transfected with NF-KB-luc (a) or AP-1-luc (b). Forty-eight hours after transfection, cells were treated with the indicated concentrations of WBP $\left(12.5-100 \mu \mathrm{g} \mathrm{ml} \mathrm{l}^{-1}\right)$ for $1 \mathrm{~h}$. Luciferase activities were determined by luminometry. Any significant differences between WBP-treated and control groups were analyzed using the Student's $t$-test ( $\left.{ }^{*} p<0.05\right)$. (c) RAW264.7 cells $\left(5 \times 10^{6}\right.$ cells ml $\left.^{-1}\right)$ were incubated with $100 \mu \mathrm{g} \mathrm{ml}^{-1}$ WBP for the indicated periods of time. The nuclear fractions were collected and protein levels of c-Jun, c-fos, p65, and $\beta$-actin were determined by immunoblotting analysis as described in Materials and methods. A representative gel graph from three independent experiments was shown. 
p38 cascades and can activate the transcription of several targets such as NF- $\mathrm{KB}$ and AP-1, or other transcription factors.[41] Recent studies have reported that polysaccharides derived from Ganoderma atrum, Platycodon grandiflorum, and Coriolus versicolor induce immunocyte activation through MAPK phosphorylation.[42-44] Therefore, we attempted to demonstrate the WBPmediated activation of three MAPK pathways during macrophage activation. We performed immunoblot analysis using anti-phospho-ERK1/2, anti-phospho-JNK, anti-phosho-p38, anti-total-ERK1/2, anti-total-JNK, and anti-total-p38 antibodies (Figure 5(a)). A time course experiment showed that the activation of p38 MAP kinase increased within $30 \mathrm{~min}$ and remained high during a 180-min treatment. However, the total amounts of JNK, p38, and ERK were not affected by WBP treatment. To further confirm the activation of p38 MAP kinase by WBP, we used SB239063 (an inhibitor of p38 MAPK) to confirm the mechanisms underlying $\mathrm{NO}, \mathrm{PGE}_{2}$, and TNF- $\alpha$ regulation of RAW 264.7 cells by WBP. Real-time PCR showed that $10 \mu \mathrm{M}$ SB239063 blocked WBPinduced iNOS, COX-2, and TNF- $\alpha$ expression by 44.77 , 38.64 , and $67.55 \%$, respectively at non-toxic doses (Figure 5(b)). These results suggest that the p38 MAPK signaling pathway is critical for WBP-mediated activation in macrophages.

TLRs play a key role in innate immune responses to enhance the body's defense system against bacteria by binding polysaccharide to macrophages, in turn resulting in an inflammatory response.[45]

A
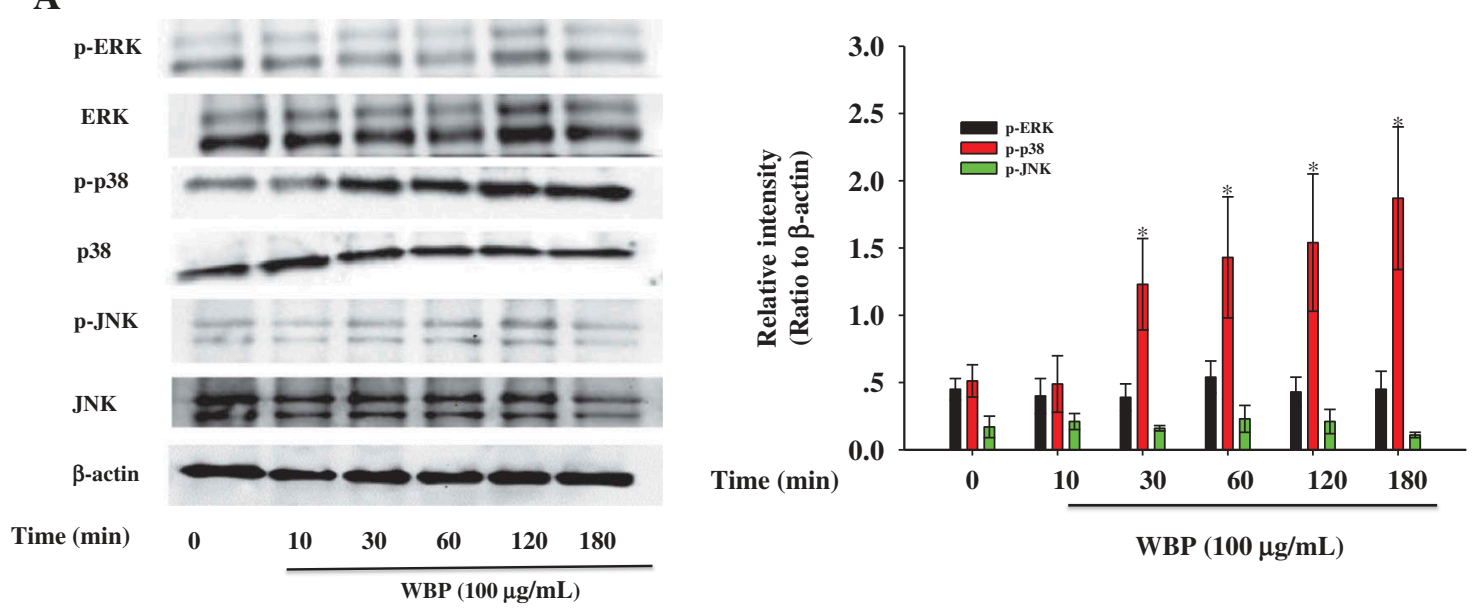

WBP $(100 \mu \mathrm{g} / \mathrm{mL})$

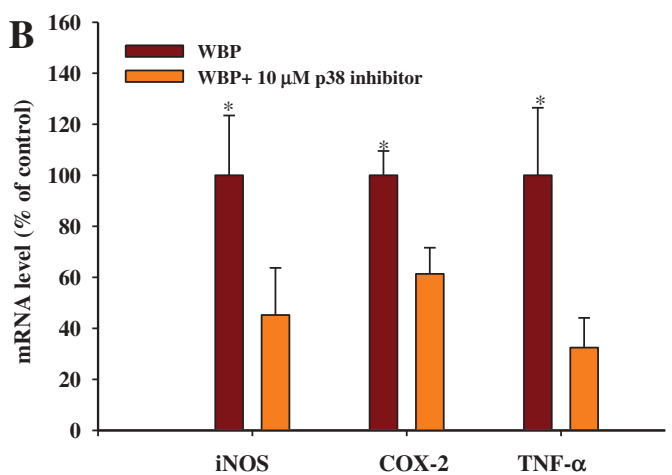

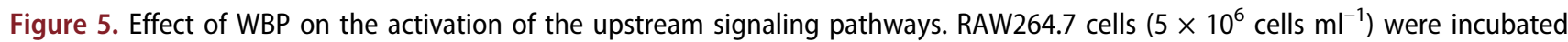
with $100 \mu \mathrm{g} \mathrm{ml}^{-1}$ WBP for the indicated periods of time. (a) The whole-cell lysates were extracted for immunoblotting to determine the levels of phospho- or total MAPKs (ERK, p38, and JNK) identified based on their antibodies. (b) Inhibitory effects of specific inhibitors p38 MAPK kinase (SB203580) on iNOS, COX-2, and TNF- $a$ expression in RAW 264.7 cells. Cells were pre-treated with SB203580 followed by stimulation with $100 \mu \mathrm{g} \mathrm{ml} l^{-1}$ WBP for $6 \mathrm{~h}$. Total RNA was isolated and real time-PCR was performed to determine the mRNA level of each gene with gene-specific primer. Within a column, any significant differences between p38 inhibitor-treated and -untreated groups were analyzed using the Student's $t$-test $\left.{ }^{*} p<0.05\right)$. (c) RAW 264.7 cells $\left(5 \times 10^{6}\right.$ cells $\left.\mathrm{ml}^{-1}\right)$ were incubated with $100 \mathrm{\mu g} \mathrm{ml}^{-1}$ WBP for the indicated periods of time. The whole-cell lysates were extracted for immunoblotting to determine the level of TLR4. (d) Inhibitory effects of anti-TLR4 on WBP-induced NO production in RAW 264.7 cells. Cells were treated with anti-TLR4 or control lgG fraction $\left(10 \mu \mathrm{g} \mathrm{ml}^{-1}\right)$ for $30 \mathrm{~min}$ followed by stimulation with different concentration of WBP $\left(25,50\right.$, or $\left.100 \mu \mathrm{g} \mathrm{ml}^{-1}\right)$ for $24 \mathrm{~h}$. The level of NO was detected by Griess reagent. Any significant differences between treatments with anti-TLR4 and control antibody were analyzed using the Student's $t$-test $\left({ }^{*} p<0.05\right)$. 


\section{C \\ TLR4 \\ $\beta$-actin}

Time (min)

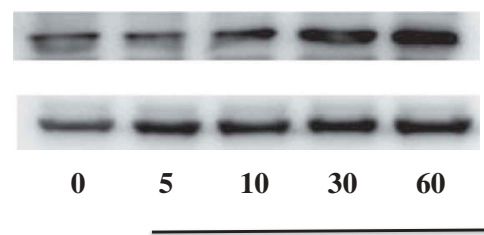

WBP $(100 \mu \mathrm{g} / \mathrm{mL})$
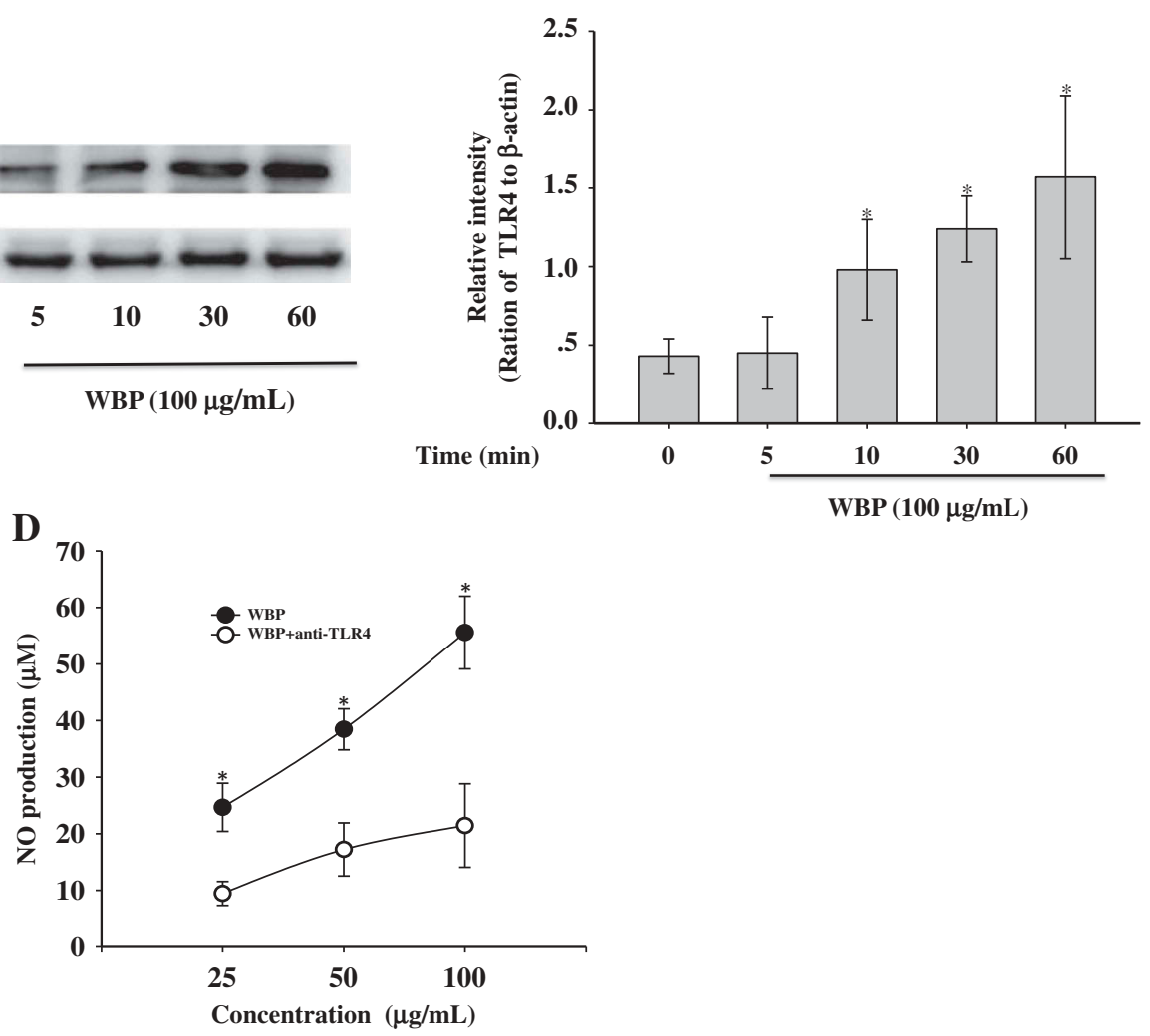

WBP $(100 \mu \mathrm{g} / \mathrm{mL})$

Figure 5. (continued)

Moreover, TLR4 is known to facilitate intracellular signaling pathways leading to activation of MAPKs, such as ERK, JNK, and p38, as well as transcription factors such as NF- $\kappa B$ and AP-1.[46] Recently, various natural polysaccharides, such as polysaccharides from Laminaria japonica, Polyporus umbellatus, and Astragalus membranaceus have been reported to trigger the activation of macrophages via the TLR4 receptor.[47-49] We hypothesized that TLR4 might be a candidate receptor/binding site for WBP. To determine the underlying signaling mechanism by which WBP promotes $\mathrm{p} 38 \mathrm{MAPK}$, cells were stimulated with $100 \mu \mathrm{g} \mathrm{ml}^{-1}$ WBP for various lengths of time $(5,10,30$, and $60 \mathrm{~min})$ and analyzed by Western blot. As shown in Figure 5(c), the TLR4 expression first increased at $10 \mathrm{~min}$ and reached a maximum in $60 \mathrm{~min}$. Furthermore, WBP-induced NO production in RAW 264.7 macrophages was partly inhibited by pre-treatment with anti-TLR4. These results suggest that the existence of a receptor other than TLR4 on macrophages that recognizes WBP is also possible, because the anti-TLR4 did not completely inhibit the production of cytokines. Further experiments will be conducted to detect other membrane receptor and/or intracellular receptors.
Effects of WBP on spleen, liver, and kidney indices and cytokine secretion in CTX-treated mice

The immune system is the main contributor to host defense against infection, as well as serving as a healing process for repairing damaged tissue.[50] Immunosuppression is a state of temporary or permanent immunity dysfunction that can make organisms more sensitive to pathogens.[51] CTX, an alkylating agent, is used widely for the establishment of animal models of immune suppression.[52] The spleen and thymus are the two main immune organs in the body. Cytokines are peptides and low-molecular weight proteins that play a prominent role in cell-cell communication in the immune response.[53] As shown in Table 4, the administration of CTX can significantly $(p<0.05)$ reduce the relative spleen and thymus weights compared with the control group, indicating a successful immunosuppression model. After WBP administration, the spleen indices increased significantly compared with the model control. The levels of IL- 2 and IFN- $\gamma$ decreased significantly in CTXtreated mice relative to those of the model control $(p<0.05)$. However, WBP markedly promoted IL-2 and IFN- $\gamma$ production to an extent close to that of the control group (Table 5). Interestingly, the immune 
Table 4. Effect of WBP on immune organ indices in the CTXtreated mice.

\begin{tabular}{lcc}
\hline Groups & $\begin{array}{c}\text { Thymus index } \\
\left(\mathrm{mg} \mathrm{g}^{-1}\right)\end{array}$ & $\begin{array}{c}\text { Spleen index } \\
\left(\mathrm{mg} \mathrm{g}^{-1}\right)\end{array}$ \\
\hline Normal control & $3.77 \pm 0.24^{*}$ & $2.98 \pm 0.23^{*}$ \\
CTX & $2.64 \pm 0.20$ & $2.06 \pm 0.12$ \\
CTX+WBP $\left(50 \mathrm{mg} \mathrm{kg}^{-1}\right)$ & $2.82 \pm 0.25$ & $2.32 \pm 0.10^{*}$ \\
CTX+WBP $\left(100 \mathrm{mg} \mathrm{kg}^{-1}\right)$ & $3.02 \pm 0.13^{*}$ & $2.67 \pm 0.21^{*}$ \\
CTX+WBP $\left(200 \mathrm{mg} \mathrm{kg}^{-1}\right)$ & $3.12 \pm 0.18^{*}$ & $2.63 \pm 0.13^{*}$ \\
\hline
\end{tabular}

Each value is presented as mean $\pm \mathrm{SD}(n=10)$.

${ }^{*} p<0.05$ compared to CTX group.

Table 5. Effect of WBP on cytokines secretion in in the CTX-treated mice.

\begin{tabular}{lcc}
\hline Groups & $\mathrm{IL}-2\left(\mathrm{pg} \mathrm{ml}^{-1}\right)$ & $\mathrm{IFN}-\gamma\left(\mathrm{pg} \mathrm{ml} \mathrm{I}^{-1}\right)$ \\
\hline Normal control & $15.72 \pm 3.23^{*}$ & $21.35 \pm 4.54^{*}$ \\
CTX & $8.57 \pm 1.45$ & $14.54 \pm 1.54$ \\
CTX+WBP $\left(50 \mathrm{mg} \mathrm{kg}^{-1}\right)$ & $9.34 \pm 2.36$ & $15.45 \pm 2.32$ \\
CTX+ WBP $\left(100 \mathrm{mg} \mathrm{kg}^{-1}\right)$ & $11.43 \pm 1.03^{*}$ & $17.24 \pm 1.34^{*}$ \\
CTX+ WBP $\left(200 \mathrm{mg} \mathrm{kg}^{-1}\right)$ & $11.67 \pm 0.98^{*}$ & $18.61 \pm 1.21^{*}$ \\
\hline
\end{tabular}

Each value is presented as mean \pm SD $(n=10)$.

${ }^{*} p<0.05$ compared to CTX group.

function in normal mice treated with a high WBP dose (200 $\mathrm{mg} \mathrm{kg}^{-1}$ body weight) did not differ significantly from that of the control group (data not shown). Together, these findings suggested that WBP may inhibit immunodeficiency in immunosuppressed mice, and have no influence on normal immune function.

\section{Conclusions}

The results of this work indicated that the polysaccharides from wheat bran can promote the immune functions of macrophages via regulating NF- $\kappa \mathrm{B}, \mathrm{AP}-1$, and $\mathrm{p} 38$ MAPK signaling pathways. Furthermore, our in vivo evidence revealed that WBP reversed immunosuppression in CTX-treated mice by increasing the spleen and thymus indices, promoting the production of inflammatory cytokines. Thus, WBP might be a potential candidate for application in functional foods. This study provides a basis for comprehensive exploration of wheat bran resources. Further study of the structural features of the polysaccharides and their molecular mechanism of modulating immune function are in progress.

\section{Disclosure statement}

No potential conflict of interest was reported by the authors.

\section{Funding}

This study was supported financially by Natural Science Foundation of Jiangsu Province [BK20150414], Natural Science Foundation of the Higher Education Institutions of Jiangsu Province [14KJB550002 and 15KJB550001], National
Natural Science Foundation of China [31600281], Top-notch Academic Programs Project of Jiangsu Higher Education Institutions [PPZY2015A018], and Qing Lan Project of Jiangsu Province.

\section{References}

[1] Galluzzi L, Buqué A, Kepp O, et al. Immunogenic cell death in cancer and infectious disease. Nat Rev Immunol. 2017;17:97-111.

[2] Tartey S, Takeuchi O. Pathogen recognition and tolllike receptor targeted therapeutics in innate immune cells. Int Rev Immunol. 2017;6:1-17.

[3] Berraondo P, Minute L, Ajona D, et al. Innate immune mediators in cancer: between defense and resistance. Immunol Rev. 2016;274:290-306.

[4] Ohta T, Kusano K, Ido A, et al. Silkrose: A novel acidic polysaccharide from the silkmoth that can stimulate the innate immune response. Carbohydr Polym. 2016;136:995-1001.

[5] Zhang Q, Lv X, Wu T, et al. Composition of Lycium barbarum polysaccharides and their apoptosis-inducing effect on human hepatoma SMMC-7721 cells. Food Nutr Res. 2015;59:28696.

[6] Jiao R, Liu Y, Gao H, et al. The anti-oxidant and antitumor properties of plant polysaccharides. Am J Chin Med. 2016;44:463-488.

[7] Xie SZ, Liu B, Zhang DD, et al. Intestinal immunomodulating activity and structural characterization of a new polysaccharide from stems of Dendrobium officinale. Food Funct. 2016;7:2789-2799.

[8] Liu J, Willför S, Xu C. A review of bioactive plant polysaccharides: biological activities, functionalization, and biomedical applications. Bioact Carbohydr Dietary Fibre. 2015;5:31-61.

[9] Wu L, Fan N, Lin M, et al. Anti-inflammatory effect of spilanthol from Spilanthes acmella on murine macrophage by down-regulating LPS-induced inflammatory mediators. J Agric Food Chem. 2008;56:2341-2349.

[10] Zhang L, Wang -C-C. Inflammatory response of macrophages in infection. Hepatobiliary Pancreat Dis Int. 2014;13:138-152.

[11] Lee JS, Hong EK. Immunostimulating activity of the polysaccharides isolated from Cordyceps militaris. Int Immunopharmacol. 2011;11:1226-1233.

[12] Ren L, Perera C, Hemar Y. Antitumor activity of mushroom polysaccharides: a review. Food Funct. 2012;3:1118-1130.

[13] Pan C, Fan Y, Hou H. Fermentative production of hydrogen from wheat bran by mixed anaerobic cultures. Ind Eng Chem Res. 2008;47:5812-5818.

[14] Stevenson L, Phillips F, O'Sullivan K, et al. Wheat bran: its composition and benefits to health, a european perspective. Int J Food Sci Nutr. 2012;63:1001-1013.

[15] Mendis M, Simsek S. Arabinoxylans and human health. Food Hydrocolloid. 2014;42:239-243.

[16] Li W, Pickard MD, Beta T. Effect of thermal processing on antioxidant properties of purple wheat bran. Food Chem. 2007;104:1080-1086.

[17] Hromádková Z, Paulsen BS, Polovka M, et al. Structural features of two heteroxylan polysaccharide fractions 
from wheat bran with anti-complementary and antioxidant activities. Carbohydr Polym. 2013;93:22-30.

[18] Chen Y, Xie MY, Nie SP, et al. Purification, composition analysis and antioxidant activity of a polysaccharide from the fruiting bodies of Ganoderma atrum. Food Chem. 2008;107:231-241.

[19] Cho ML, Yang C, Sang M-K. Molecular characterization and biological activities of water soluble sulfated polysaccharides from Enteromorpha prolifera. Food Sci Biotechnol. 2010;19:525-533.

[20] $\mathrm{Hu} \mathrm{W}, \mathrm{Wu} \mathrm{L}$, Qiang Q, et al. The dichloromethane fraction from Mahonia bealei (Fort.) Carr. leaves exerts an anti-inflammatory effect both in vitro and in vivo. J Ethnopharmacol. 2016;188:134-143.

[21] $\mathrm{Hu} \mathrm{W}, \mathrm{Wang} \mathrm{X}, \mathrm{Wu} \mathrm{L}$, et al. Apigenin-7-O- $\beta$-D-glucuronide inhibits LPS-induced inflammation through the inactivation of AP-1 and MAPK signaling pathways in RAW 264.7 macrophages and protects mice against endotoxin shock. Food Funct. 2016;7:1002-1013.

[22] Wu L, Li X, Wu H, et al. 5-Methoxyl aesculetin abrogates lipopolysaccharide-induced inflammation by suppressing MAPK and AP-1 pathways in RAW 264.7 cells. Int J Mol Sci. 2016;17:315.

[23] $\mathrm{Hu}$ W, Wang G, Li P, et al. Neuroprotective effects of macranthoin $G$ from Eucommia ulmoides against hydrogen peroxide-induced apoptosis in PC12 cells via inhibiting NF-kB activation. Chem Biol Interact. 2014;224:108-116.

[24] Zhou S, Liu X, Guo Y, et al. Comparison of the immunological activities of arabinoxylans from wheat bran with alkali and xylanase-aided extraction. Carbohyd Polym. 2010;81:784-789.

[25] Tao Y, Zhang Y, Zhang L. Chemical modification and antitumor activities of two polysaccharide-protein complexes from Pleurotus tuber-regium. Int J Biol Macromol. 2009;45:109-115.

[26] Arcila JA, Weier SA, Rose DJ. Changes in dietary fiber fractions and gut microbial fermentation properties of wheat bran after extrusion and bread making. Food Res Int. 2015;74:217-223.

[27] Snelders J, Dornez E, Delcour JA, et al. Courtin, Impact of wheat bran derived arabinoxylanoligosaccharides and associated ferulic acid on dough and bread properties. J Agric Food Chem. 2014;62:7190-7199.

[28] Wang CZ, Zhang HY, Li WJ, et al. Chemical constituents and structural characterization of polysaccharides from four typical bamboo species leaves. Molecules. 2015;20:4162-4179.

[29] He S, Wang X, Zhang Y, et al. Isolation and prebiotic activity of water-soluble polysaccharides fractions from the bamboo shoots (Phyllostachys praecox). Carbohydr Polym. 2016;151:295-304.

[30] Hotchkiss RS, Monneret G, Payen D. Immunosuppression in sepsis: a novel understanding of the disorder and a new therapeutic approach. Lancet Infect Dis. 2013;13:260-268.

[31] Moretti J, Blander JM. Insights into phagocytosiscoupled activation of pattern recognition receptors and inflammasomes. Curr Opin Immunol. 2014;26:100-110.

[32] Lee JS, Kwon DS, Lee KR, et al. Mechanism of macrophage activation induced by polysaccharide from
Cordyceps militaris culture broth. Carbohydr Polym. 2015;120:29-37.

[33] Lei H, Luo S, Qin H, et al. Molecular mechanisms of endothelial NO synthase uncoupling. Curr Pharm Des. 2013;20:3548-3553.

[34] Lasry A, Zinger A, Benneriah Y. Inflammatory networks underlying colorectal cancer. Nat Immunol. 2016;17:230-240.

[35] Lee KY, Jeon YJ. Polysaccharide isolated from Poria cocos sclerotium induces $\mathrm{NF}-\kappa \mathrm{B} / \mathrm{Rel}$ activation and iNOS expression in murine macrophages. Int Immunopharmacol. 2003;3:1353-1362.

[36] Lee KY, You HJ, Jeong HG, et al. Polysaccharide isolated from Poria cocos sclerotium induces NF-kappaB/ Rel activation and iNOS expression through the activation of p38 kinase in murine macrophages. Int Immunopharmacol. 2004;4:1029-1038.

[37] Jose GM, Kurup GM. The efficacy of sulfated polysaccharides from Padina tetrastromatica in modulating the immune functions of RAW 264.7 cells. Biomed Pharmacother. 2017;88:677-683.

[38] Gill SK, Islam N, Shaw I, et al. Immunomodulatory effects of natural polysaccharides assessed in human whole blood culture and THP-1 cells show greater sensitivity of whole blood culture. Int Immunopharmacol. 2016;36:315-323.

[39] Mauriz JL, Collado PS, Veneroso C, et al. A review of the molecular aspects of melatonin's anti-inflammatory actions: recent insights and new perspectives. J Pineal Res. 2013;54:1-14.

[40] Lee MS, Kwon MS, Choi JW, et al. Anti-inflammatory activities of an ethanol extract of Ecklonia stolonifera in lipopolysaccharide-stimulated RAW 264.7 murine macrophage cells. J Agric Food Chem. 2012;60:9120-9129.

[41] Thalhamer T, McGrath MA, Harnett MM. MAPKs and their relevance to arthritis and inflammation. Rheumatology (Oxford). 2008;47:409-414.

[42] Yu Q, Nie SP, Wang JQ, et al. Polysaccharide from Ganoderma atrum induces tumor necrosis factor- $\alpha$ secretion via phosphoinositide 3-kinase/Akt, mitogenactivated protein kinase and nuclear factor- $\mathrm{\kappa B}$ signaling pathways in RAW264.7 cells. Int Immunopharmacol. 2012;14:362-368.

[43] Yoon YD, Kang J-S, Han SB, et al. Activation of mitogen-activated protein kinases and AP-1 by polysaccharide isolated from the radix of Platycodon grandiflorum in RAW 264.7 cells. Int Immunopharmacol. 2004;4:1477-1487.

[44] Yang SF, Zhuang TF, Si YM, et al. Coriolus versicolor mushroom polysaccharides exert immunoregulatory effects on mouse B cells via membrane Ig and TLR-4 to activate the MAPK and NF- $\mathrm{BB}$ signaling pathways. Mol Immunol. 2015;64:144-151.

[45] Tosi MF. Innate immune responses to infection. J Allergy Clin Immunol. 2005;116:241-249.

[46] Liu Y, Yin H, Zhao M, et al. TLR2 and TLR4 in autoimmune diseases: a comprehensive review. Clin Rev Allergy Immunol. 2014;47:136-147.

[47] Fang Q, Wang JF, Zha XQ, et al. Immunomodulatory activity on macrophage of a purified polysaccharide 
extracted from Laminaria japonica. Carbohydr Polym. 2015;134:66-73.

[48] Li X, Xu W. TLR4-mediated activation of macrophages by the polysaccharide fraction from Polyporus umbellatus (pers. Fries J Ethnopharmacol. 2011;135:1-6.

[49] Wei W, Xiao HT, Bao WR, et al. TLR-4 may mediate signaling pathways of Astragalus polysaccharide RAP induced cytokine expression of RAW264.7 cells. J Ethnopharmacol. 2015;179:243-252.

[50] Jr CAJ. How the immune system protects the host from infection. Microbes Infect. 2001;3:1167-1171.
[51] Fan Y, Lu Y, Wang D, et al. Effect of epimedium polysaccharide-propolis flavone immunopotentiator on immunosuppression induced by cyclophosphamide in chickens. Cell Immunol. 2013;281:37-43.

[52] Huyan XH, Lin YP, Gao T, et al. Immunosuppressive effect of cyclophosphamide on white blood cells and lymphocyte subpopulations from peripheral blood of Balb/c mice. Int Immunopharmacol. 2011;11:1293-1297.

[53] Cekici A, Kantarci A, Hasturk H, et al. Inflammatory and immune pathways in the pathogenesis of periodontal disease. Periodontol. 2014;64:57-80. 